\title{
Research About the Casting Technique of Chu-style Bronze Tripod
}

\author{
Yanling Yuan \\ Collegue of History and \\ Chongqing Normal University \\ Chongqing, P. R. China \\ e-mail: yuanyanling622@gmail.com
}

\author{
Peiyao He \\ College of History and Society \\ Chongqing Normal University \\ Chongqing, P. R. China \\ e-mail: pyjadehe@gmail.com
}

\begin{abstract}
According to the different shape characteristics, the Chu-style tripods can be divided into five categories: tripod with rim bent outside, tripod with string-rim, tripod with rim bent inside, flat-bottomed tripod, water-heating tripod. The main casting technique of Chu-style tripods is multiple casting. And the main cast of the tripods is $3-0+1$, their join-traces usually are IVb, the shape of the sprue is generally strip and most of the sprues are on the bottom of the tripod. On the basis of the shape and the size of the Chu-style tripods, the cast may be different, such as the the cast of the exquisitely flatbottomed tripod is $6-0+1$, and the cast of some the simpleshape and small tripod with string-rim or water-heating tripod is $2-\mathbf{N}+1$.
\end{abstract}

\section{Keywords-Chu-style tripod; casting method; cast}

\section{INTRODUCTION}

Chu culture is a highly developed and unique style regional culture of southern China in the period from Eastern Zhou to the Qin Dynasty. Meanwhile, bronze tripod is an important kind of ritual vessels in Chinese culture. Chu bronze tripod is an important ritual of Chu culture. Many tombs of Eastern Zhou Dynasty in Henan, Hubei province exposed a lot of bronze Ding of the Chu culture, such as Xichuan Xiasi tomb, Heshangling tomb and Xujialing cemetery, Hubei Jingmenbaoshan tomb. Morphological analysis of the bronze Ding of Chu culture in Eastern Zhou Dynasty, written by Mr. Gao Chongwen, is one of the representative article about the bronze Ding of Chu culture. He divided the Chu style tripod into seven types: A、B、 CI、CII、D、E、F. [1] The present article refers to Mr. Liu Binhui' s Research about Chu-style bronze [2], according to the shape characteristics of the Chu-style bronze Ding, Chu-style bronze Dings are divided into five categories: tripod with rim bent outside , tripod with stringrim 、 tripod with rim bent inside flat-bottomed tripod、 water-heating tripod, and preliminary observe the casting technology of the different categories, then research the casting technology system of the Chu-style bronze Ding.

\section{CASTING TECHNOLOGY}

Generally there are two kinds of casting technology of bronze tripod: integral casting method and multiple casting method. The multiple casting method is the most common production technology in the Eastern Zhou period. According to the casting sequencing, multiple casting method can be divided to appendages cast first and cast after. There are some kinds of technologies connect the appendages to the body as follows:

1) Inlay the appendages on the mold of the vessel body: this is a technique that cast the appendages advance and assemble them on the mold of the vessel body. Length of the appendages can not exceed the cavity of the molds. Afterwards, the appendages will be connected with vessel body while casting the vessel body. In order to make the appendages and the vessel body are combined firmly without falling, the junctions of the legs, the ears, the lid knobs and rob-handles usually are cast chunks.

2) Inlay the appendages on the vessel body: firstly,casting the vessel body, on the vessel body where need to set appendages should set aside square socket for casting and casting the appendages such as ears, legs and so on with chunk on the junctions. Secondly, dig up some clay from the clay model of the chunk so that there can be a pit for casting. Finally, the appendages should be fixed to the square casting socket and cast from the other side of the socket, the copper solution in the pit form a mushroomshaped chunk so that the appendages can be firmly stuck to the vessel body.

3) Welding: welded connection method is casting the vessel body at first. Tenons should be set aside on the vessel body where need to set appendages, and the appendages should be cast followed. Then a pit will be dug up in the weld, following the solder will be put into the socket and let the tenons sheathe in the solder. There is another casting method called medium casting method, which set a metal spacer whose thickness is similar to the vessel body with three tenons between the ears and mouth, one of the tenons is up and the other two are down. The clay should be dug up from the ears. Then, the upward tenon will be inserted into the ears, and the other two tenons will be fixed to the corresponding position on the vessel body. Finally, the ears will be connected firmly with vessel body while casting the vessel body.

4) Inlay the mold of the appendages on the vessel body: this technique is usually used for casting small appendages. Firstly, square socket should be set aside on the corresponding position when casting the vessel body. 
Secondly, the mold of the appendages will be fixed to the socket, and a pouring need to be put cup on the other side of the socket. Finally, the appendages should be connected firmly with vessel body while casting the appendages.

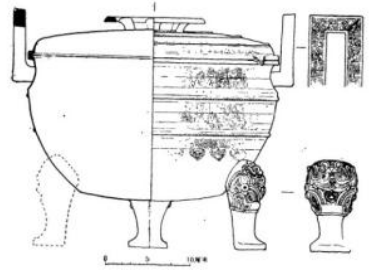

Figure 1.Tripod with rim bent outside

\section{TRIPOD WITH RIM BENT OUTSIDE}

This tripod has side ears, bent outside rim and contracted neck(see Fig 1), the number of this kind of ding unearthed from each tomb is very rare,generally only one or two. The Xiasi tomb no. 1 and no.2, unearthed the most, in the former is four, the later is five.

The specimen 62 [3] from the Xiasi tomb no.1 in the late period of the Spring and Autumn Era,has lid, contracted neck,side ears round bottom and hoof legs, its height is $28 \mathrm{~cm}$, the diameter of it's mouth is $31.5 \mathrm{~cm}$, the mold of the bottom is triangle, and there is a strip-shape socket in the middle of the bottom. The height of the specimen 66 [4] from the Xiasi tomb no. 1 is $45 \mathrm{~cm}$, the diameter of the mouth is $57.5 \mathrm{~cm}$, the mold of the bottom is round, and also have a strip-shape socket in the middle of the bottom. The specimen 11 [5] from the Xiasi tomb no.3 has lid, contracted neck, side ears, hoof legs and nearly flat bottom, the height is $46 \mathrm{~cm}$, the diameter of the mouth is $47 \mathrm{~cm}$, the mold of the bottom is round.

The Xujialing tomb no.1 and no.10 are in the early period of the Warring States, the specimen 1 [6] from the Xujialing tomb no. 1 has a lid, contracted neck, medium mouth, side ears, nearly flat bottom and hoof legs, the height is $31.6 \mathrm{~cm}$, the diameter of mouth is $33.6 \mathrm{~cm}$. And the cast is 3 - o +1 . It's ears and hoof legs are used the first method to cast. The specimen 46 [7] from the Xujialing tomb no. 10 has contracted neck, side ears, flat bottom and hoof legs, it's height is $56.8 \mathrm{~cm}$, the diameter of mouth is 55.2. And the cast is 4-O+1, it's ears and hoof legs are also used the first method to cast. As Mr. Tanba Takashi demonstrated the induction about join-trace in a paper[8], the join-trace of the specimen 46 from the Xujialing tomb no.10 is IVd.(see Fig. 2)

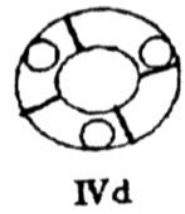

Figure 2. IVd

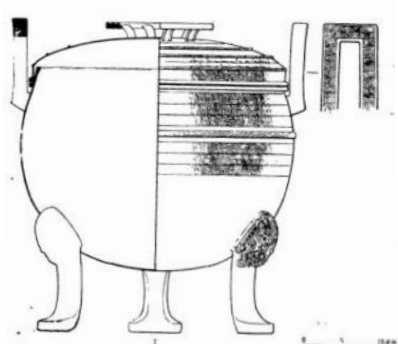

Figure 3. Tripod with string-rim

\section{TRIPOD WITH STRING-RIM}

Near the mouth of this tripod, there is a circle of belt for sustaining the lid.(see Fig.3)

The specimens 57 [9] and 67 [10] were unearthed from the Xiasi tomb no.1. The height of the former is $41.34 \mathrm{~cm}$, the later is $41.6 \mathrm{~cm}$. The diameter of the mouth of the former is $32.5 \mathrm{~cm}$, and the later is $33 \mathrm{~cm}$. Both of them have triangular molds of bottom and strip-shape socket for casting in the middle of the bottom. The date of the Xiasi tomb no. 11 is the late period of the Spring and Autumn Era.

The specimen 3 [11] from the Xiasi tomb no.11 has contracted mouth, deep belly, side ears, round bottom and highly hoof legs. The height of it is $39.8 \mathrm{~cm}$, the diameter of mouth is $33.5 \mathrm{~cm}$, the cast is $3-0+1$. The sprue and rising head may be on the edge of mouth, this indicate that the specimen 3 from the Xiasi tomb no.11 may be casting when the mouth is upward.

The specimens 32 [12] and 29 [13] were unearthed from the Heshangling tomb no.2, the date of the no. 2 is the late period of the Spring and Autumn Era. The height of the former is $28 \mathrm{~cm}$, the later is $34.8 \mathrm{~cm}$. The diameter of the mouth is $23 \mathrm{~cm}$ and $30 \mathrm{~cm}$. The specimen 39 [14] was unearthed from Xujialing cemetery no.3, the height of it is $25.5 \mathrm{~cm}$, the diameter of mouth is $20.5 \mathrm{~cm}$. The ears and legs of these three Ding above are all cast by the first method. All of their cast are 3-o+1.

The style of Jichou Ding [15]( Height $53.4 \mathrm{~cm}$ ), which was unearthed from Lisangudui Chu tomb in Anhui Province, is similar to the specimen 32 from Heshangling cemetery no.2. The side ears, three hoof legs and lid knob were cast advance, this was the same as the production technique on most Ding since the late period of Spring and Autumn period. However, it is special that the three mold marks on the belly of the Ding correspond to three legs. Usually, in order to seal off the three legs better when composite the molds, the traces of the position where compositing the molds are not coincide with the three legs. This production technique is also very rare in other group of bronze of Chu culture in the Warring States period. The production technique and the decoration of King Chu, Yinken tripod(now in the Palace Museum)is similar to the above one.

\section{TRIPOD WITH RIM BENT INSIDE}

The edge of the mouth of this tripod is fold inward, and the rim stretches upward and bents inside ( see Fig. 4 ) 


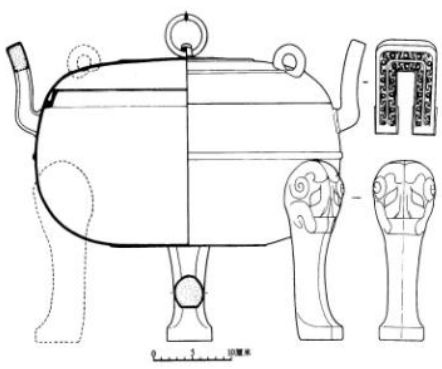

Figure 4. Tripod with rim bent inside

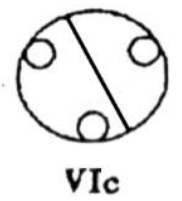

Figure 5. VIc

The date of the specimen 6 [18] from the Xiasi tomb no.7 is the middle period of Spring and Autumn Era. It has deep and bulged belly, side ears, round bottom and hoof legs, the height is $32 \mathrm{~cm}$, the diameter of the mouth is $25 \mathrm{~cm}$, the cast of this specimen is $3-\Delta+1$, and in the middle of the bottom mold there is a strip-shape sprue. All ears and legs are cast before the vessel body.

The specimens 5 [19] ( Height $37.6 \mathrm{~cm}$, diameter of mouth $34 \mathrm{~cm}$ )and 2 [20](Height $22.4 \mathrm{~cm}$, diameter of mouth $23 \mathrm{~cm}$ )from the Xujialing tomb no.1. Their casts is $4-?+1$ ( Can not see the shape of the bottom mold), and their ears and legs were all welded on the vessel body. The specimen 3 [21](Height $27.4 \mathrm{~cm}$, Diameter of mouth $30.2 \mathrm{~cm}$ )from the Xujialing tomb no.1, the specimen 44 [22](remained height $19.2 \mathrm{~cm}$,Diameter of the mouth $26.2 \mathrm{~cm}$ )from the Xujialing tomb no.1, the specimen 5 [23] from the Xujialing tomb no.10(Height $35.8 \mathrm{~cm}$,Diameter of the mouth $33 \mathrm{~cm}$ ) and the specimen 50 [24](Height $28 \mathrm{~cm}$,Diameter of the mouth 25 $\mathrm{cm})$ from the Xujialing tomb no.10. The casts of those above are 3-?+1 ( Can not see the shape of the bottom mold), and their ears and legs are all cast on the vessel body by the first method.

The date of the Jingmen Baoshan Chu tomb no.2 [25] is the Warring States, and the ears and legs of the specimens 106 ( Height $30 \mathrm{~cm}$, Diameter of mouth $26.3 \mathrm{~cm}$ ), 150(Height $21.6 \mathrm{~cm}$, Diameter of mouth $16.2 \mathrm{~cm}$ ), 132(Height $26.4 \mathrm{~cm}$, Diameter of mouth $22 \mathrm{~cm}$ ), 140(Height $26.6 \mathrm{~cm}$, Diameter of mouth $20.8 \mathrm{~cm}$ ) and 105 ( Height $47.8 \mathrm{~cm}$, Diameter of mouth $40.9 \mathrm{~cm}$ ), are all cast by multiple casting method. The casts of them are $3-0+1$, and the sprues are on the commissure of the belly molds and the bottom molds. The mold of the specimens 173, 140 and 127 is exactly similar, the size of these three is from the largest to the smallest. But the number of their sectional molds of belly are all three.

In group B of Jianglingjiudian tomb in Eastern Zhou dynasty, there had been unearthed eight A type III-style Dings, six of them only have two sectional molds without any bottom mold to composite. As same as the B type IIIstyle Ding 250:19(Height $17.4 \mathrm{~cm}$, Diameter of mouth 13.4 $\mathrm{cm})$. The casts of those seven above are $2-\mathrm{N}+1$, and their join-traces are VIc ( see Fig.5 ). The casts of the others are mostly $3-0+1$ [26].

The specimens 87 [27] from the Warring States Bailuzhou tomb 566 in Anhui Province has bulged belly, nearly flat round bottom and three hoof legs, the height of it is $27.6 \mathrm{~cm}$, the diameter is $20.3 \mathrm{~cm}$. There is a convex line under the convex bowstring grain on the belly through the bottom, this line is the mark of compositing molds. It leads that the cast of this one may be $2-\mathrm{N}+1$, and the join-trace is VIc. In addition, there are another tripod with rim bent inside [28] which are from the north of city and the kiln factory in the west of city in Luan Anhui province also have the same join-trace, VIc. [29]

\section{FLAT-BOTTOMED TRIPOD}

The Flat-bottomed tripod known as Sheng is the typical ritual vessel ( see Fig. 6) The characteristic of it is that it has trumpet mouth, outward vertical ears, contracted waist and flat bottom. It is recognized as a important Archaeological features in the Chu culture. And observation about the production technique of Sheng is helpful to the study on the casting system of the Bronze of the Chu culture.



Figure 6. Flat-bottomed tripod

This kind of tripod was unearthed from many tombs of Chu culture such as Xichuan Xiasi tomb, Heshangling tomb and Xujialing cemetery, and Jingmen Baoshan tomb of Chu culture. Among these, those Sheng from the Xiasi tomb are exquisite. For instance, in the tomb no.2 there are seven Wangzi Wu-Sheng [30], the molding of them is exactly similar, the size of these three is from the largest to the smallest. The height of the biggest one is $68 \mathrm{~cm}$, of the smallest one is $61.3 \mathrm{~cm}$. The diameter of the mouth of the biggest one is $66 \mathrm{~cm}$, of the smallest is $58 \mathrm{~cm}$. They all have lid, trumpet mouth, the square rim deflexed outward, outward vertical ears, little contracted neck, contracted waist, little bulged belly, flat bottom and hoof legs. There are decorated curved and hooked forms derived from animal elements, interlaced-hydras design and double ring pattern on the vessel body, and half-round appendage on the waist. Six exquisite strange beasts are on the vessel body. The specimen 38 ( Height $67.4 \mathrm{~cm}$, Diameter of mouth $66 \mathrm{~cm}$ ) from the Xiasi tomb no.2. And there are bird-style expression curved inside of the tripod and the bottom, convex line in the form of a cross on the bottom, this line may be the reinforcing strands. Although the specimen 34 from the Xiasi tomb no. 2 was broken, we can also clearly observe the sprue, rising head and the convex line in the form of a cross. After observation about these, we can see 
Wangzi Wu-Sheng has round molds of the bottom, the stripshape sprue in the middle of the bottom and the strip-shape rising head in the round. The cast of Wangzi Wu-Sheng is $6-0+1$, the number of the molds of bottom are four, one of it in the middle is round. The ears, legs and the appendage were cast advance, then inlaying them to the corresponding position on vessel body. The ears may be connected with the vessel body by medium casting method. And the legs were welding on the vessel body: casting ring forms with big mouth and small bottom in the corresponding positions on the bottom. These ring form can be rivets to make the legs connecting to the vessel body firmly.

The specimen 55 [31](Height $63 \mathrm{~cm}$, Diameter of mouth $62.3 \mathrm{~cm}$ ) from the Xiasi tomb no.1 has square rim bent outward, vertical ears, contracted waist, flat bottom, hoof legs and a round of appendage. And six strange beasts are on the vessel body. We can see a ear cushion for welding at the root of one of the ears, and the sprue, rising heads and the marks of assembling the molds clearly.

However, the Sheng from the Xujialing cemetery are coarse, such as the specimens from the tomb no.3 [32]. The join-trace of the specimen 41(Height 40, Diameter of mouth $38 \mathrm{~cm}$ )from the tomb no.3 is IVb ( see Fig. 7 ). The ears of the specimen 35 ( Height $38.5 \mathrm{~cm}$, Diameter of mouth 34 $\mathrm{cm})$ from the tomb no. 3 were cast on the vessel body. The cast of the specimen 11 [33](Height $31.8 \mathrm{~cm}$, Diameter of mouth $29.8 \mathrm{~cm}$ ) from the Xujialing cemetery no. 9 is $3-0+1$, and the smaller ones specimen 36 (Height $29.2 \mathrm{~cm}$, Diameter of mouth $28 \mathrm{~cm}$ ) and specimen 34 ( Height 33.2 $\mathrm{cm}$, Diameter of mouth $31.6 \mathrm{~cm}$ ), both from the Xujialing cemetery no.3, have two sectional molds of the belly, their casts are $2-0+1$, the join-traces of them are IVc ( Fig. 8 ). Almost all of the flat-bottomed tripods which were unearthed from Xujialing cemetery had the ears welded on, and their bottom molds are round.

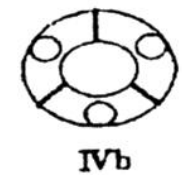

Figure 7. IVb

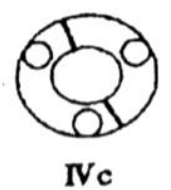

Figure 8. IVc

There are specimen 45(Height $35.5 \mathrm{~cm}$, Diameter of mouth 39.1)cm, specimen 44(Height $27.2 \mathrm{~cm}$, Diameter of mouth $31.5 \mathrm{~cm}$ )and specimen 43(Height $32.5 \mathrm{~cm}$, Diameter of mouth $37 \mathrm{~cm}$ ) unearthed from the no.10 tomb in Xujialing. The cast of the specimen 43 is $3-0+1$, the ears of it were welded on and the other appendages were cast on the vessel body. And the cast of the specimen 35(Height 32.5 $\mathrm{cm}$, Diameter of mouth $37 \mathrm{~cm}$ ) is $4-0+1$, it's ears and legs were cast by the first method. [34]
The date of the Caihou tomb in Shou county (Anhui Province) is the Spring and Autumn Era. The specimen SCM: 1 [35] with a large size ( Height $69 \mathrm{~cm}$, Diameter of mouth $62 \mathrm{~cm}$ ), which from this tomb, had the three legs connected with the vessel body by the first method. The cast of SCM: 1 is $4-0+1$ and in the middle of the bottom there is a strip-shape sprue. The specimens SCM:2.1-2.7 [36] have six appendages on the belly, the cast of these is 6 $0+1$, and in the bottom there is mark in the form of Y which was left by casting. And the appendages were cast first and then connected with the belly, the ears and legs were cast after. There are another nine with lids [37], Mr. Guo Baojun observed one of these nine in the China National Museum, he found that the cast of the one is $2-\mathrm{N}+1$, there is no mold of the bottom [38].

\section{WATER-HEATING TRIPOD}

The characteristics of this tripod is having the vertical collar, small mouth, broad shoulder, round belly and three hoof legs, the ears stand straightly or outward on the shoulder.( see Fig. 9 )

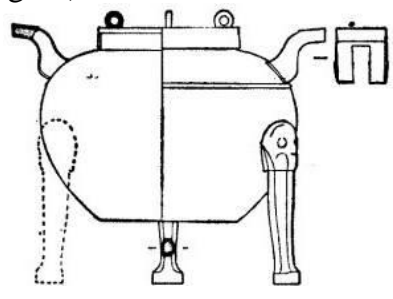

Figure 9. Water-heating tripod

The specimen 70 [39] (Height $33 \mathrm{~cm}$, Diameter of mouth $19.5 \mathrm{~cm}$ )from the Xiasi tomb no. 1 has vertical collar, round shoulder, bulged belly, vertical ears on the shoulder, little round bottom and three hoof legs. It's bottom mold is round, and a strip-shape sprue in the middle of the bottom. The specimen 4 [40](Height $40.5 \mathrm{~cm}$, Diameter of mouth $22.5 \mathrm{~cm}$ )from the Xiasi tomb no. 3 has a lid, vertical mouth, broad shoulder, vertical ears, nearly flat bottom and three hoof legs. The mold of bottom is round, and the sprue is in the bottom.

The specimen 390 [41](Height $41.2 \mathrm{~cm}$, Diameter of mouth $21.8 \mathrm{~cm}$ ) from the Chu tomb no. 2 in Baoshan has a lid, vertical mouth, arc shoulder, side ears, round belly, flat bottom, three legs. And the ears and legs were cast in the vessel body.

\section{CONCLUSION}

Through the above observations on the bronze Ding of Chu culture production technique, it is obviously that the separate casting method had been fully mastered.

The main technique of casting the bronze ding is the separate casting method. Since the middle period of Spring and Autumn, most of the tripod with rim bent outside、 tripod with rim bent inside and water-heating tripod cast their ears and legs by the method that casting the appendages advanced, then fixing them on the molds of the vessel body or the vessel body and connecting the appendages with the molds of the vessel body or the vessel 
body by casting. To the former part of the late period of the Spring and Autumn Period, the tenon and mortise were used extensively, and cast the ears and legs on the vessel body by welding. This method above is especially on the flatbottomed tripod, the legs of the flat-bottomed tripod were all welding on, and a part of the ears were connected with the vessel body by medium casting method. However, there are some from the Caihou tomb in Shou county Anhui Province were cast ears and legs after.

Generally, the bottom mold of the ding of Chu culture is round, the cast is $3-0+1$, the join-trace is like $I V b$, the shape of the sprue is like strip, and it is often in the middle of the bottom, this illustrate that the Ding is downward when it was casting. But according to the different size and different characteristics of the shape, there are different cast. Such as the cast of the exquisitely ones with many appendages is $6-0+1$; And some little and simple-shape tripod with string-rim and water-heating tripod just have two sectional molds, the cast of them is $2-\mathrm{N}+1$, the appearance of this cast is the sign about that casting the legs by multiple casting method had become normalization. Owing to cast the legs separated, and decorating the legs by printing, the mold of bottom can be merged with the molds of belly. This embodied the purport of the least molds to form the vessel.

Mr.Tanba Takashi think the cast of $2-\mathrm{N}+1$, which different from the cast in Jianghan region, is the typical feature of the bronzes which were unearthed from the Liu'an county in the south of Anhui Province [42]. But by the observation above, this cast method was also found in the bronzes which were unearthed in Shou county of Anhui Province and Jiudian in Jiangling. Therefore, Mr.Tanba Takashi needs to rethink his point of view.

\section{REFERENCES}

[1] Gao Chongwen, "Morphological analysis of the bronze Ding of Chu culture in Eastern Zhou Dynasty," Jianghan kaogu , vol.1, 1983, pp. $1-18$

[2] Liu Binghui, Research about Chu-style bronze, Hubei Education Press, 1995, pp. 111-130

[3] Institute Of Cultural Relics In Henan Province, Xichuan Xiasi Chunqiu Chu mu, Beijing, Wenwu publishing House, 1991, pp. 54

[4] Institute Of Cultural Relics In Henan Province, Xichuan Xiasi Chunqiu Chu mu , Beijing, Wenwu publishing House, 1991, pp. 54

[5] Institute Of Cultural Relics In Henan Province, Xichuan Xiasi Chunqiu Chu mu, Beijing, Wenwu publishing House, 1991, pp. 218

[6] Institute Of Cultural Relics In Henan Province, Heshangling yu Xujialing Chu mu, Wenwu publishing House, 2004, pp. 221

[7] Institute Of Cultural Relics In Henan Province, Heshangling yu Xujialing Chu mu, Wenwu publishing House, 2004, pp. 249

[8] Tanba Takashi, Chu Wenhua yanjiu lunji, vol:7, Yuelu Publishing House

[9] Institute Of Cultural Relics In Henan Province, Xichuan Xiasi Chunqiu Chu mu, Beijing, Wenwu publishing House, 1991, pp. 52

[10] Institute Of Cultural Relics In Henan Province, Xichuan Xiasi Chunqiu Chu mu , Beijing, Wenwu publishing House, 1991, pp. 52

[11] Institute Of Cultural Relics In Henan Province, Xichuan Xiasi Chunqiu Chu mu , Beijing, Wenwu publishing House, 1991, pp. 293

[12] Institute Of Cultural Relics In Henan Province, Heshangling yu Xujialing Chu mu, Wenwu publishing House, 2004, pp. 27
[13] Institute Of Cultural Relics In Henan Province, Heshangling yu Xujialing Chu mu, Wenwu publishing House, 2004, pp. 27

[14] Institute Of Cultural Relics In Henan Province, Heshangling yu Xujialing Chu mu, Wenwu publishing House, 2004, pp. 126

[15] Zhang Changping, Nanfang Wenwu, Vol. 2, 2012, pp. 160-161

[16] Zhang Changping, Nanfang Wenwu, Vol. 2, 2012, pp. 160-161

[17] Zhang Changping, Nanfang Wenwu, Vol. 2, 2012, pp. 160-161

[18] Institute Of Cultural Relics In Henan Province, Xichuan Xiasi Chunqiu Chu mu, Beijing, Wenwu publishing House, 1991, pp. 28

[19] Institute Of Cultural Relics In Henan Province, Heshangling yu Xujialing Chu mu, Wenwu publishing House, 2004, pp. 219

[20] Institute Of Cultural Relics In Henan Province, Heshangling yu Xujialing Chu mu, Wenwu publishing House, 2004, pp. 221

[21] Institute Of Cultural Relics In Henan Province, Heshangling yu Xujialing Chu mu, Wenwu publishing House, 2004, pp. 220

[22] Institute Of Cultural Relics In Henan Province, Heshangling yu Xujialing Chu mu, Wenwu publishing House, 2004, pp. 221

[23] Institute Of Cultural Relics In Henan Province, Heshangling yu Xujialing Chu mu, Wenwu publishing House, 2004, pp. 251

[24] Institute Of Cultural Relics In Henan Province, Heshangling yu Xujialing Chu mu, Wenwu publishing House, 2004, pp. 251

[25] Hubei Province Tielu Kaogu Dui, Baoshan Chu mu,Wenwu publishing House, 1995, pp. 98-101

[26] Institute Of Cultural Relics In Hubei Province, Jiangling Jiudian dongzhou mu, Science Press, 1995, pp. 201-205

[27] Institute Of Cultural Relics In Anhui Province, Administration of cultural relics In Luan, Kaogu, Vol. 5, 2012, pp. 29-40

[28] Chu Jinhua, Wenwu, Vol. 1, 1993 ; Administration of cultural relics In Luan, Kaogu, Vol. 2, 1995.

[29] Tanba Takashi, Chu Wenhua yanjiu lunji, vol:7, Yuelu Publishing House

[30] Institute Of Cultural Relics In Henan Province, Xichuan Xiasi Chunqiu Chu mu, Beijing, Wenwu publishing House, 1991, pp. 112

[31] Institute Of Cultural Relics In Henan Province, Xichuan Xiasi Chunqiu Chu mu, Beijing, Wenwu publishing House, 1991, pp. 54

[32] Institute Of Cultural Relics In Henan Province, Heshangling yu Xujialing Chu mu, Wenwu publishing House, 2004, pp. 125-126

[33] Institute Of Cultural Relics In Henan Province, Heshangling yu Xujialing Chu mu, Wenwu publishing House, 2004, pp. 174

[34] Institute Of Cultural Relics In Henan Province, Heshangling yu Xujialing Chu mu, Wenwu publishing House, 2004, pp. 248-249

[35] Su Rongyu, Hua Jueming, Li Keming, Lu Benshan, Zhongguo Shanggu Jinshu jishu, Shandong Science \& Technology Press, 1995, pp. 161-162

[36] Su Rongyu, Hua Jueming, Li Keming, Lu Benshan, Zhongguo Shanggu Jinshu jishu, Shandong Science \& Technology Press, 1995, pp. $161-162$

[37] Su Rongyu, Hua Jueming, Li Keming, Lu Benshan, Zhongguo Shanggu Jinshu jishu, Shandong Science \& Technology Press, 1995, pp. $161-162$

[38] Su Rongyu, Hua Jueming, Li Keming, Lu Benshan, Zhongguo Shanggu Jinshu jishu, Shandong Science \& Technology Press, 1995, pp. 161-162

[39] Institute Of Cultural Relics In Henan Province, Xichuan Xiasi Chunqiu Chu mu , Beijing, Wenwu publishing House, 1991, pp. 54

[40] Institute Of Cultural Relics In Henan Province, Xichuan Xiasi Chunqiu Chu mu, Beijing, Wenwu publishing House, 1991, pp. 218

[41] Hubei Province Tielu Kaogu Dui, Baoshan Chu mu,Wenwu publishing House, 1995, pp. 102

[42] Tanba Takashi, Chu Wenhua yanjiu lunji, vol:7, Yuelu Publishing House 